\title{
Numerical simulation of a tsunami event during the 1996 volcanic eruption in Karymskoye lake, Kamchatka, Russia
}

\author{
T. Torsvik ${ }^{1}$, R. Paris ${ }^{2}$, I. Didenkulova ${ }^{3,4}$, E. Pelinovsky ${ }^{4}$, A. Belousov ${ }^{5}$, and M. Belousova ${ }^{5,6}$ \\ ${ }^{1}$ Bergen Center for Computational Science, Uni Research, Bergen, Norway \\ ${ }^{2}$ CNRS-GEOLAB, Clermont-Université, 4 rue Ledru, 63057 Clermont-Ferrand, France \\ ${ }^{3}$ Laboratory of Wave Engineering, Institute of Cybernetics, Tallinn, Estonia \\ ${ }^{4}$ Department of Nonlinear Geophysical Processes, Institute of Applied Physics, Nizhny Novgorod, Russia \\ ${ }^{5}$ Earth Observatory of Singapore, Nanyang Technological University, Singapore \\ ${ }^{6}$ Institute of Volcanology \& Seismology, Petropavlovsk-Kamchatsky, Russia
}

Received: 21 July 2010 - Revised: 11 October 2010 - Accepted: 14 October 2010 - Published: 22 November 2010

\begin{abstract}
Karymskoye caldera lake is a nearly circular body of water with a diameter of approximately $4 \mathrm{~km}$ and a depth of up to $60 \mathrm{~m}$. The sublacustrine, Surtseyan-type eruption in the lake on 2-3 January 1996 included a series of underwater explosions. A field survey conducted the following summer showed signs of tsunami wave runup around the entire coastline of the lake, with a maximum of $29 \mathrm{~m}$ runup at the north shore near the source of the eruption, and $2-5 \mathrm{~m}$ runup at locations on the east and south shore far away from the source.

The tsunami has been simulated using the numerical long wave model COULWAVE, with input from reconstructed realistic pre-eruption bathymetry. The tsunami source was chosen as suggested by Le Mehaute (1971) and Mirchina and Pelinovsky (1988). The initial wave was prescribed by a parabolic shape depression with a radius of $R=200 \mathrm{~m}$, and a height of $23 \mathrm{~m}$ at the rim of the parabola. Simulations were conducted to show principle directions for wave propagation, wave speed and arrival time for the leading wave group at the shore, and the distribution of wave height throughout the lake. Estimated result for wave runup are of the same order of magnitude as field measurements, except near the source of the eruption and at a few locations where analysis show significant wave breaking.
\end{abstract}

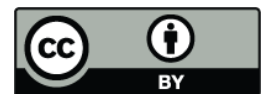

Correspondence to: T. Torsvik (tomas.torsvik@uni.no)

\section{Introduction}

About $25 \%$ of all the fatalities directly attributable to volcanoes during the last 250 years have been caused by volcanic tsunamis (Begét, 2000), both by eruptive processes (e.g. 1883 Krakatau, 1937 Rabaul), or by collapses of volcanic cones (e.g. Iliwerung 1979, Paluweh 1928, Mount Mayuyama 1792). Volcanic explosions caused 25\% of the volcanic tsunamis reported for the four last centuries (Latter, 1981). They usually deposit small volumes of material $\left(<1 \mathrm{~km}^{3}\right)$ compared to ignimbrites, caldera subsidences or flank collapses $\left(1-100 \mathrm{~km}^{3}\right)$ and travel shorter distances $(<$ $50 \mathrm{~km}$ ), but may generate deadly local tsunamis, especially in relatively small, shallow bodies of water like bays or lakes. Such events are known from case studies in Kamchatka (Belousov and Belousova, 2001; Belousov et al., 2000) and in Nicaragua (Freundt et al., 2007), and the possibility of producing an effective warning system has been discussed (Bellotti et al., 2009). The 2-3 January 1996 sublacustrine eruption and subsequent tsunamis that occurred in Karymskoye lake (Kamchatka, Russia) represents a unique opportunity to model tsunamis generated by volcanic explosions.

Karymskoye lake is a nearly circular, bowl-like water body, approximately $4 \mathrm{~km}$ in diameter, having steep flanks and a nearly flat bottom with depths of 50-62 m (Figs. 1 and 2). A new, partly submerged crater, with an inner diameter of 500-550 m, was formed by the 1996 eruption near the north shore of the lake (Fig. 3).

Published by Copernicus Publications on behalf of the European Geosciences Union. 


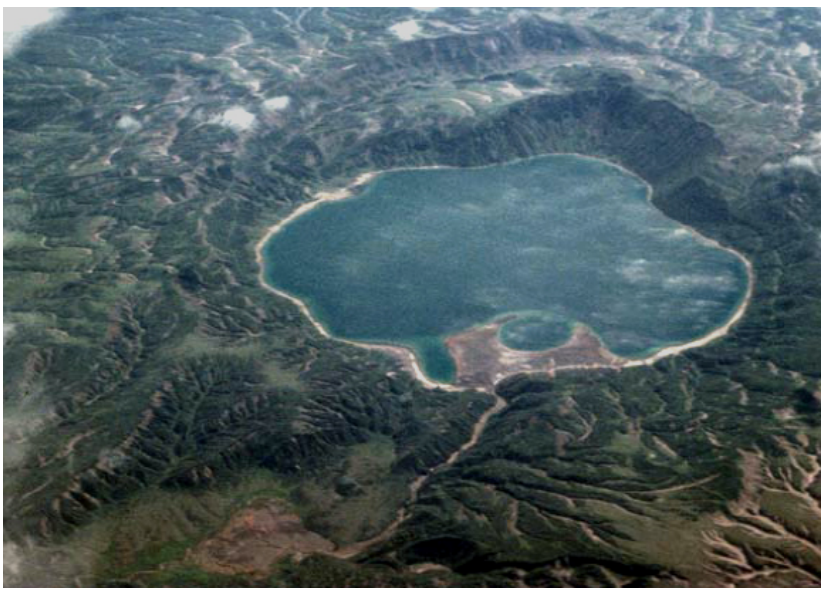

Fig. 1. Aerial photograph of Karymskoye caldera lake, taken from the North. The horse-shoe shaped structure in the northern part of the lake is a partly submerged crater formed by the 1996 eruption. Photograph by A. Belousov, September 1996.

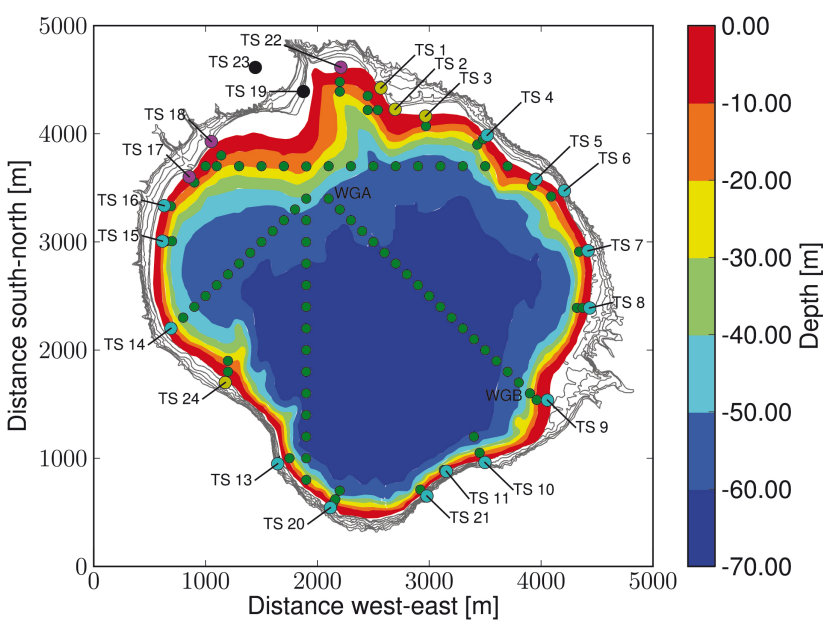

Fig. 2. Bathymetry of Karymskoye lake, and topographic contours of the lake shore each $5 \mathrm{~m}$. Markers indicate location of runup measurement sites (cyan, yellow, magenta, black) and of 91 numerical wave gauges (green).

Belousov and Belousova (2001) described one of the strongest observed explosions as follows: a rapidly rising $(\sim 3 \mathrm{~s})$, smooth-surfaced bulbous mass of gas and pyroclasts expands within a shell of water up to $450 \mathrm{~m}$ high and then becomes unstable and is pierced by cypressoid jets of pyroclasts with gas and water. Initial velocity of these jets is estimated as $110 \mathrm{~m} \mathrm{~s}^{-1}$. Simultaneously, a bore-like elevation of the water surface starts to propagate radially at about $20-40 \mathrm{~m} \mathrm{~s}^{-1}$. Within $\sim 15 \mathrm{~s}$ from the beginning of the explosion, the jets reach their maximum height of about $1 \mathrm{~km}$ and then collapse back toward the lake to produce a
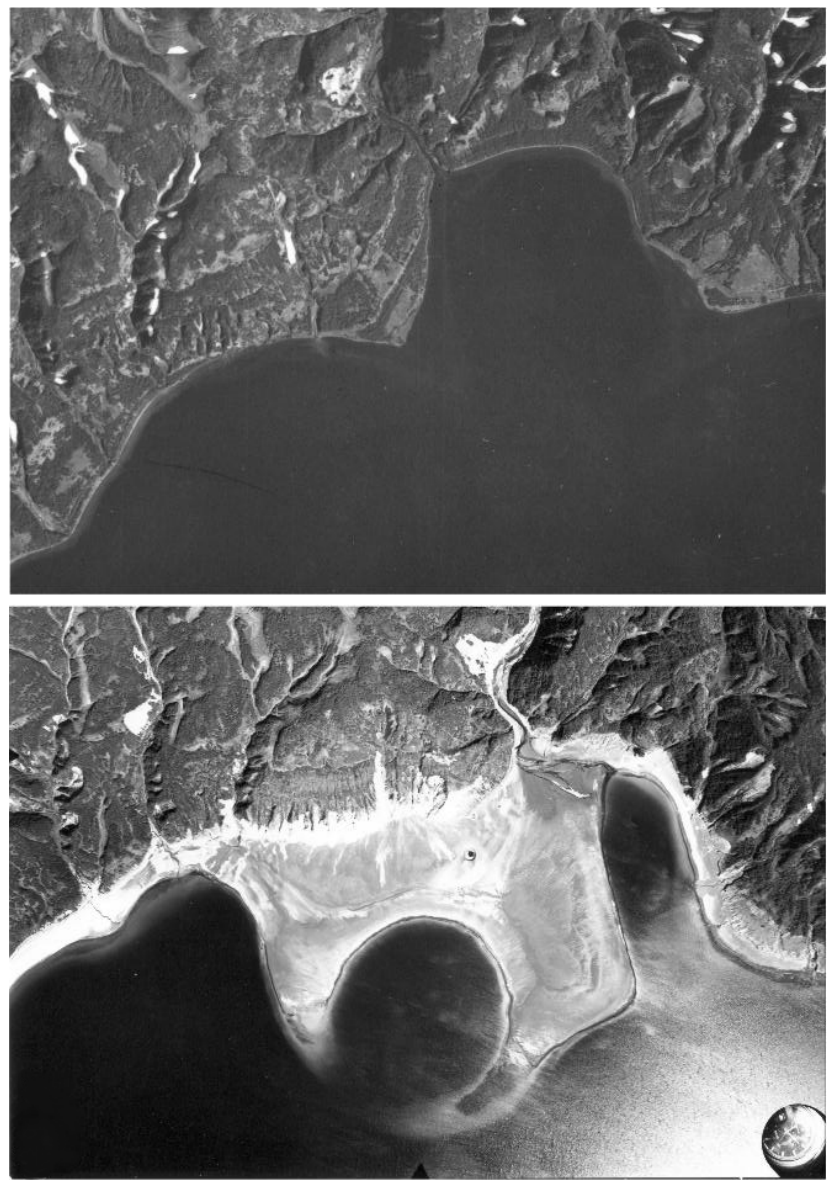

Fig. 3. Vertical aerial photographs of the 1996 eruption site in the northern part of Karymskoye lake. The upper photo shows the preeruption coastline (1984), and the lower photo shows the coastline after the eruption (August 1996). Images courtesy of Institute of Volcanology and Seismology, Russia.

base surge travelling across the lake surface at $\sim 12.5 \mathrm{~m} \mathrm{~s}^{-1}$ $(600 \mathrm{~m}$ in $48 \mathrm{~s})$. Other weaker explosions produced a single, near-vertical, column-like jet about 100-150 m high. The column then collapsed back into the lake and generated a subtle base surge.

Underwater explosions occurred every 4-12 min, with an average interval of $6 \mathrm{~min}$. Considering that the eruption lasted 10-20 h, 100-200 explosions may have occurred in the lake during the eruption (Belousov and Belousova, 2001). Tsunamis periodically affected the shores and forced water from the lake into the only outlet, the Karymskaya River, thus forming lahars. The largest of the tsunamis occurred at the end of the eruption. This may indicate that the explosions that took place near the end of the eruption were stronger than those of the main stage. Belousov and Belousova (2001) estimated that $\sim 2 \times 10^{5} \mathrm{~m}^{3}$ of tephra per explosion were emitted, corresponding to kinetic energy of $\sim 2 \times 10^{12} \mathrm{~J}$. 


\section{Review of theoretical background}

An exact mathematical description of explosion-generated water waves is not available at the moment, and would in any case be difficult to incorporate as initial condition for a long wave, shallow water model. Le Mehaute (1971) suggested an empirical formula for waves at some distance from the eruption, with initial water displacement $\eta$ and water velocity $u$ given as

$\eta(r, 0)= \begin{cases}\eta_{0}\left[2(r / R)^{2}-1\right], & r \leq R \\ 0 & r>R\end{cases}$

$u(r, 0)=0$

respectively (see also Le Méhauté and Wang, 1996). The formula for $\eta$ includes the maximum surface elevation $\eta_{0}$, the characteristic radius $R$ of the initial surface deformation, and the radial coordinate $r$ giving the distance from the source point. This formula was found to give the best agreement between linear wave theory and experiments with low energy $\left(E \sim 2 \times 10^{6}-3 \times 10^{10} \mathrm{~J}\right)$ under-water explosions (Mirchina and Pelinovsky, 1988).

The formula used by Le Mehaute (1971) is not a suitable initial condition for long wave models, because it prescribes a discontinuity of the water level at $r=R$. We have therefore modified the formula for the free surface displacement

$\eta(r, 0)=\left\{\begin{array}{lr}\eta_{0}\left[2(r / R)^{2}-1\right], & r \leq R \\ \eta_{0}\left[2(r / R)^{2}-1\right] e^{P_{\mathrm{r}}(1-r / R)}, & R<r \leq 2 R \\ 0, & r>2 R\end{array}\right.$

where the factor $P_{\mathrm{r}}$ decides the rate of decline in surface elevation for $r>R$. In the simulations for small amplitude initial disturbance we have used $P_{\mathrm{r}}=200.0$, which results in a profile that is numerically equivalent to the Le Mehaute profile.

Le Mehaute (1971) estimated the maximum wave length, group velocity, and amplitude in shallow water at a distance $r$ from the eruption center as

$\lambda_{\max } \approx 1.7 R$

$V_{\max } \approx \sqrt{g h}\left[1-6.8 \frac{h^{2}}{R^{2}}\right]$

$\eta_{\max } \approx 0.1 \eta_{0} R^{2} / h r$

where $g=9.81 \mathrm{~m} \mathrm{~s}^{-2}$ is the acceleration due to gravity The relationship between the maximum initial surface displacement (in meters) and eruption energy (in Joule) can be estimated as

$\eta_{0}=2.4 \times 10^{-2} E^{0.24}$

Based on predictions by Belousov and Belousova (2001) that the kinetic energy of the largest explosions were of the order $E \approx 2 \times 10^{12} \mathrm{~J}$, the corresponding maximum initial surface displacement according to Le Mehaute's formula is $\eta_{0}=23.0 \mathrm{~m}$. The characteristic length scale $R=200.0 \mathrm{~m}$ is determined by the radius of the caldera created by the eruptions.

\section{Methods}

\subsection{Field work}

A survey of Karymskoye lake was conducted in September 1996. Wave runup was recorded at 23 locations around the lake, as shown in Fig. 2 (note that TS12 is absent from the records). The runup represents the difference in elevation between the highest lake level during the eruption and the level reached by the inundating wave (which was marked by various material deposited by tsunami). Details can be found in Belousov and Belousova (2001). The runup data has mean value and standard deviation of $7.3 \pm 5.9 \mathrm{~m}$, with a maximum of $29 \mathrm{~m}$ runup at the north shore near the source of the eruption, and 2-5 m runup at locations on the east and south shore far away from the source.

\subsection{Reconstruction of pre-eruption model area}

Topographic maps of the area surrounding the lake are available, both for the pre-eruption and post-eruption states, but a pre-eruption bathymetry is not available. The digital elevation model of the Karymskoye lake bathymetry and shore region was constructed on a $274 \times 334$ grid with grid resolution $\Delta x=\Delta y=21.29 \mathrm{~m}$. A pre-eruption bathymetry was reconstructed based on present day data, combining topographic data from the ASTER satellite with bathymetry data obtained from a survey with an echo-sounder device ("Eagle Seacharter" with integrated GPS). Topographic changes associated with the eruption deposit were removed manually, with guidance from pre- and post-eruption aerial photographs (see Fig. 3). The pre-eruption bathymetry at the location of the new crater was estimated by extrapolating bathymetry data from the surrounding area into the region where the eruption deposits had been removed.

\subsection{Numerical simulation}

Numerical simulations have been performed using the COULWAVE model, which has been developed to simulate the evolution of fully nonlinear (wave amplitude to water depth ratio of $a / h \sim 1$ ) long waves over a variable bathymetry (Lynett and Liu, 2002; Lynett et al., 2002). The model is based on a set of weakly dispersive Boussinesqtype equations, which is a suitable framework for studying the propagation and transformation of nonlinear long waves on fairly large computational domains. This particular model has previously been used in studies of tsunami waves from various sources (Lynett and Liu, 2002; Korycansky and Lynett, 2007; Geist et al., 2009), as well as for smaller long wave phenomena such as ship waves (Torsvik et al., 2009a,b). The original model has been modified by the authors to include the initial conditions for an under-water explosion. 
Simulations were performed on a $\Delta x=\Delta y=10 \mathrm{~m}$ grid, where data for the bathymetry was further refined by interpolation. The total simulation time was $5 \mathrm{~min}$, which is sufficient time for the leading waves to propagate across the lake. A flow relaxation scheme was used on the boundaries of the numerical domain to absorb any outgoing waves, but this was of little practical use due to the absence of open boundaries. Waves reaching the coastline were reflected back into the lake.

The numerical model became unstable for large values of $\eta_{0}$, and we were not able to run the model with $\eta_{0}=23 \mathrm{~m}$. Simulations have been performed with initial wave heights of $\eta_{0}=0.23 \mathrm{~m}, 0.46 \mathrm{~m}$, and $2.3 \mathrm{~m}$. For the two first cases, the leading wave group is expected to behave like linear waves, whereas weakly nonlinear effects can be expected in the last case. The equivalence source function Eq. (1) and formulas (3) for maximum wave length, amplitude and velocity are based on linear wave theory.

The model of Le Mehaute as well as the COULWAVE model can not be used for description of the real, strongly nonlinear wave field at the center of the eruption, but the numerical and theoretical results are expected to converge towards the realistic wave field with increasing distance from the eruption center. That is why we have applied an equivalence source function that is good only for wave description in the far field. In the case of Karymskoe lake, where the model area is bounded within a fairly small area, it is difficult to make a clear distinction between the near field and far field region. Therefore we also need to include the near field region in the simulations. In order to perform the calculations without inducing too large numerical errors, we first decrease the real wave amplitude by 100 times and run the simulations for almost linear waves of small amplitude, and thereafter the same factor of 100 is multiplied back into the wave amplitude before the estimated runup heights are calculated.

The procedure described above has obviously some limitation with respect to accuracy. We test the accuracy of the procedure in two ways. Firstly, we make a comparative study between runup measurements and predictions based on the simulations and a theoretical runup formula. The results can be expected to deviate greatly for coastal regions close to the eruption center, but the deviations should decrease with increasing distance from the eruption center. Secondly, we make a comparative study between simulated results using different reduction factors $(10,50$, and 100). The purpose of this study is to ensure that the simulated results are not highly sensitive to the scaling factor.

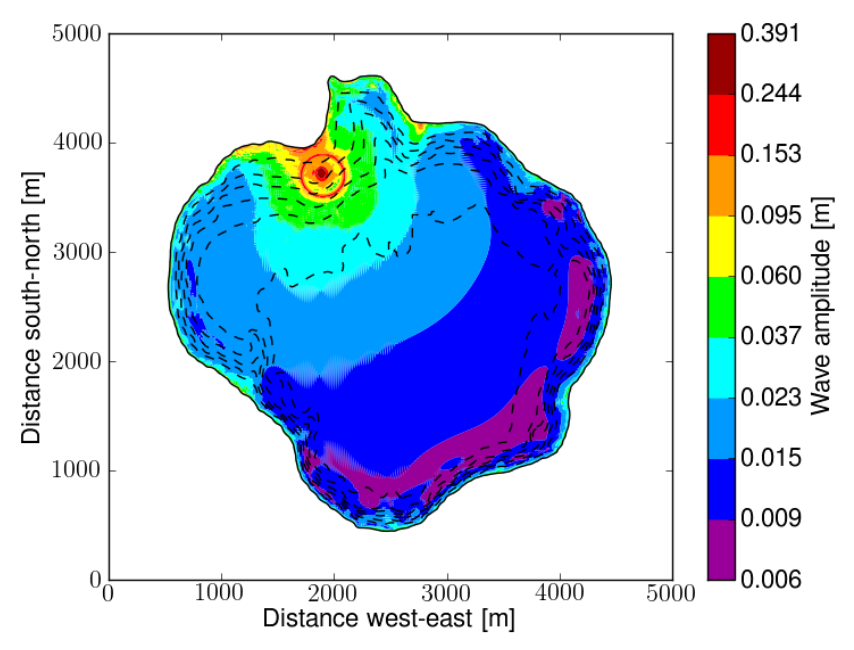

Fig. 4. Simulated maximum wave amplitude in Karymskoye lake during the 1996 eruption. The bathymetry is represented by dashed lines, which are drawn at $10 \mathrm{~m}$ depth intervals.

\section{Results}

\subsection{Linear waves}

A simulation with $\eta_{0}=0.23 \mathrm{~m}$ was used for the linear wave case. Figure 4 shows the maximum water elevation for each grid point throughout the lake. Only the maximum of the 3 leading waves have been included in the record, in order to avoid noise due to waves reflected from the shore, and in order not to take into account short crested waves that are not accurately represented by the model equations. Note that color scale in Fig. 4 is logarithmic. A circular feature indicates the extension of the initial profile, and the maximum at the center of the circle is produced when the initial profile collapses. The wave amplitude is reduced rapidly as the waves propagate away from the source area, but increase again near shore due to wave shoaling. However, the runup height is only of the same order of magnitude or less than the wave amplitude at the source, and there is generally no wave amplification in the basin. Wave amplitude near the shore is shown in more detail in Fig. 5, which shows maximum water elevation at the $5 \mathrm{~m}$ depth contour along the shore line. The strongest wave impact is seen on the north and west shores.

Figure 2 shows the location of the 91 numerical wave gauges used in the simulations, where the wave amplitude is recorded at each time step throughout the simulation. Some gauges are located along lines radiating out from the location of the eruption, while others are placed offshore measurement sites for wave runup. The panels in Fig. 6ae show the depth along different lines, maximum wave amplitude of the 3 leading waves at each wave gauge, the maximum wave amplitude predicted by Le Mehaute's theory Eqs. (3), and the mean wave speed between wave gauges. 

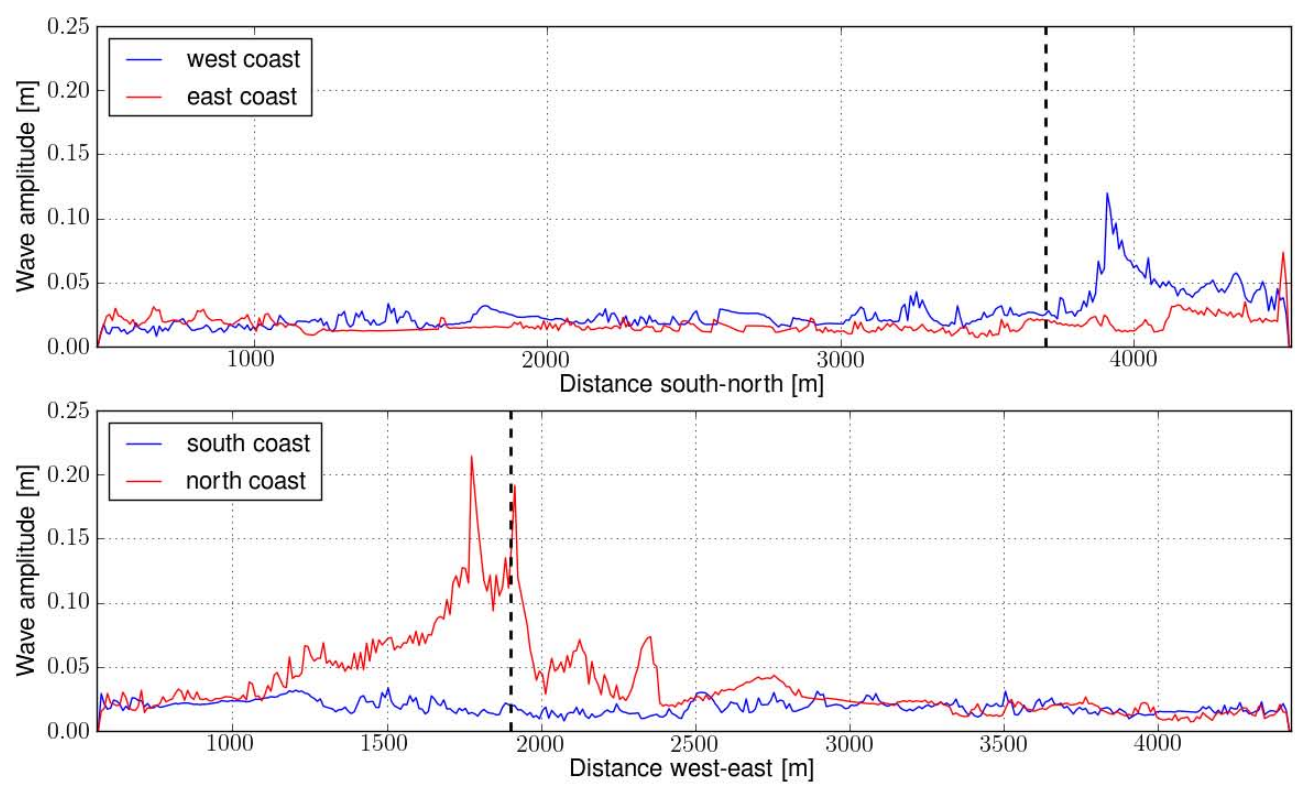

Fig. 5. Maximum wave amplitude at the $5 \mathrm{~m}$ isobath along the coast of Karymskoye lake. The location of the center of the source (crater) is indicated by a black, dashed line.

The wave speed was estimated by detecting the passing of the first wave trough at each wave gauge, as this measure is less influenced by wave-wave interaction than the wave peaks. The comparison between theory and simulations seem to be satisfactory along all radial directions, except in the case of westward wave propagation (Fig. 6a).

Wave propagation along the westward line in Fig. 6a differs from the other records since this line is located in shallow water close to the north shore. Note that the scale for the wave amplitude in Fig. 6a is larger than for Fig. 6b$\mathrm{e}$, because the first point is located nearly at the edge of the initial source. Waves propagating westward are highly influenced by wave refraction due to the close proximity to the north shore, and it is therefore not expected that the leading wave group propagates along the straight line formed by the wave gauges. This is also indicated by Fig. 6f, which show the Froude numbers

$F r_{h}=\frac{V}{\sqrt{g h}}$

along each line of propagation, calculated from the estimated wave speeds $V$ between wave gauges, the acceleration of gravity $g$, and the local depth $h$. The large values in Froude number for westward propagating waves indicate that the leading wave group does not follow the line of wave gauges, but instead originate from further offshore. The large jumps at the tails of the other Froude number records may also indicate that the wave trough measure for wave speed is inappropriate in shallow water when waves are shoaling.
Comparison between the theoretical prediction of wave amplitude and the simulated result shows that there is a similar trend in amplitude reduction with distance, but there is only a good quantitative match for waves propagating to the east (Fig. 6e). The results do not match near the eruption source and in shallow water where waves are shoaling, but this is expected since the theoretical prediction assume that waves have propagated over a long distance in water of constant depth. However, the simulated and theoretical results in Fig. $6 \mathrm{~b}-\mathrm{d}$ are converging in the deep part of the lake as the distance increases, indicating that a better match between theory and simulations could be obtained in a larger water basin.

The wave speed of the leading wave group is up to $24 \mathrm{~m} \mathrm{~s}^{-1}$ in the deepest part of the lake, and the first wave trough reaches the south-east coast approximately $140 \mathrm{~s}$ after the eruption. After an initial acceleration, the waves are seen to propagate at $F r_{h}=0.95-0.97$ in the deep part of the lake. By Le Mehaute's theory we should have $\lambda_{\max } \approx 1.7 R=$ $340 \mathrm{~m}$, and the Froude number for linear waves in water of depth $h=60.0 \mathrm{~m}$ can be estimated as

$F r_{h}=\left[\frac{\tanh \left(2 \pi h / \lambda_{\max }\right)}{2 \pi h / \lambda_{\max }}\right]^{1 / 2}=0.85$

which is significantly slower than the simulated results. A possible reason for the deviation between the theoretical and simulated results may be that the source length scale $R$ is not very large compared to the water depth $h$, and therefore linear shallow water theory may not be well suited for this problem. 


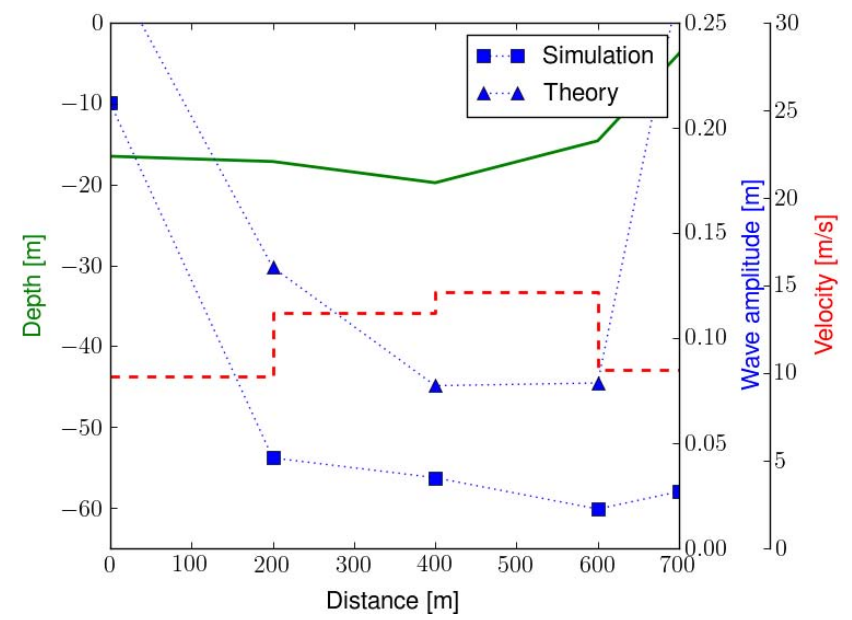

Fig. 6a. Wave propagation in west direction.

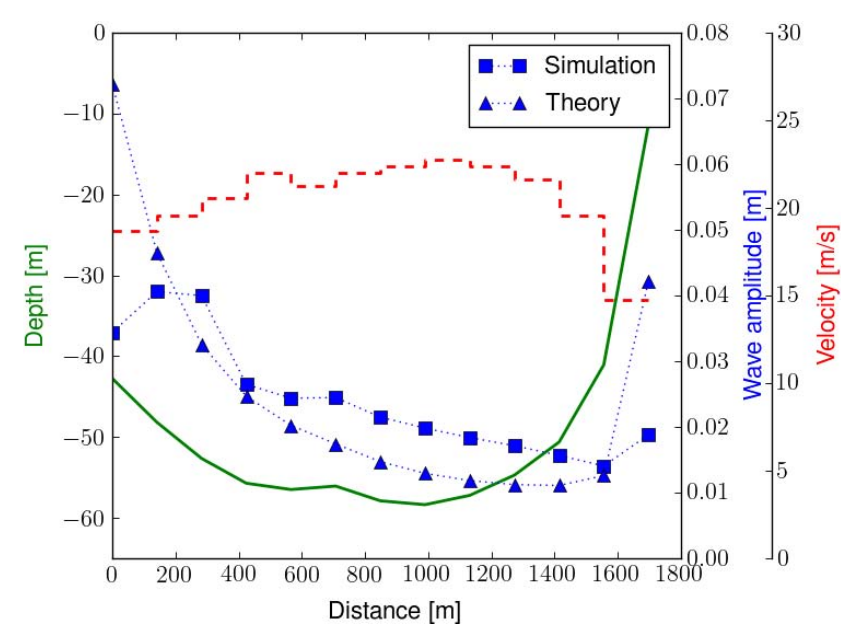

Fig. 6b. Wave propagation in south-west direction.

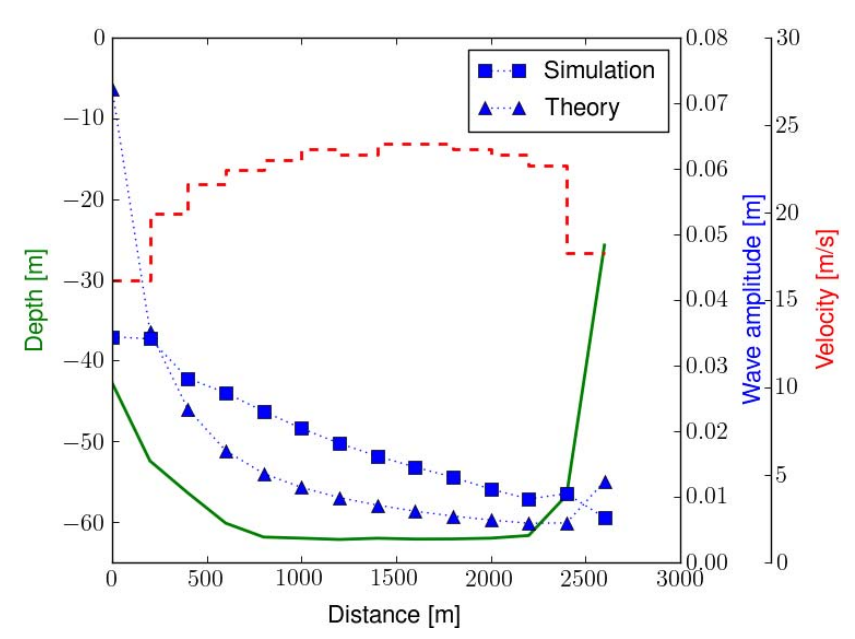

Fig. 6c. Wave propagation in south direction.

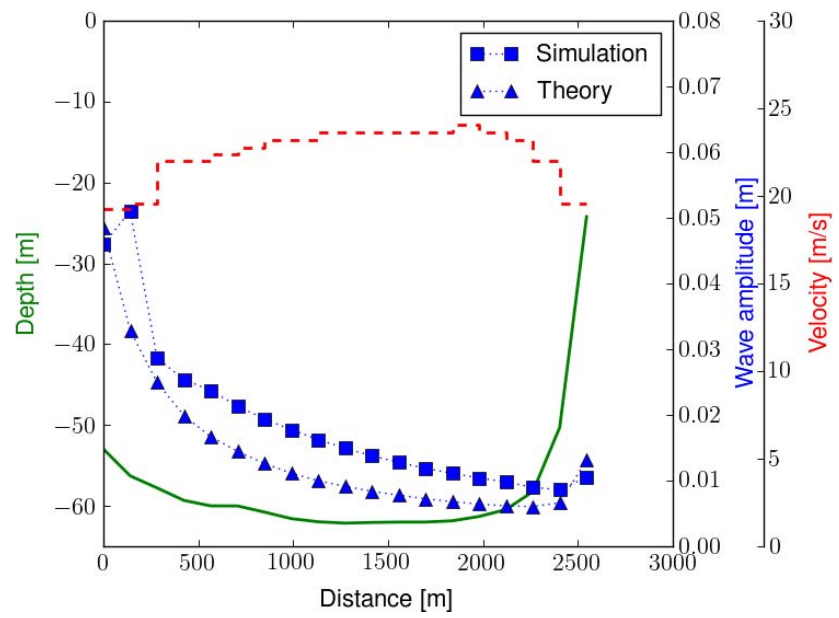

Fig. 6d. Wave propagation in south-east direction.

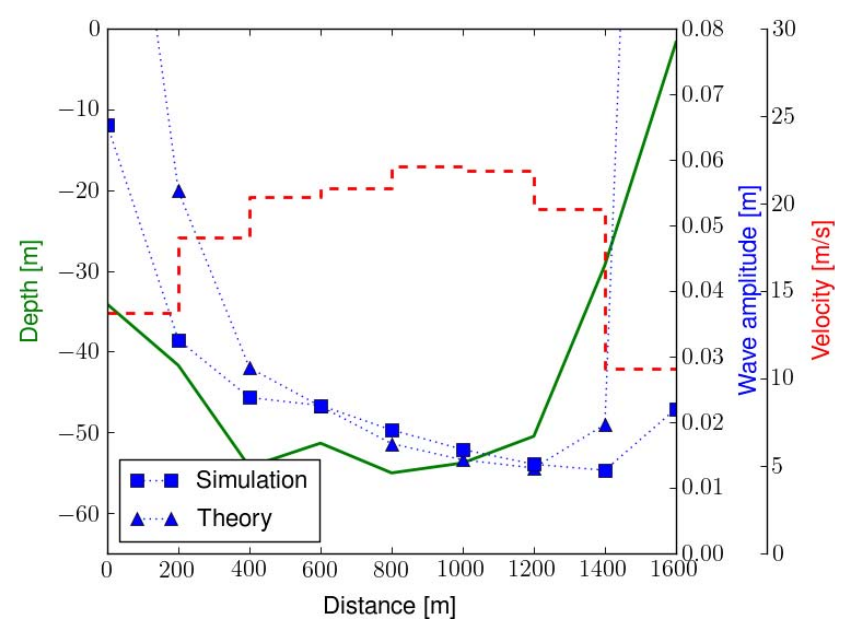

Fig. 6e. Wave propagation in east direction.

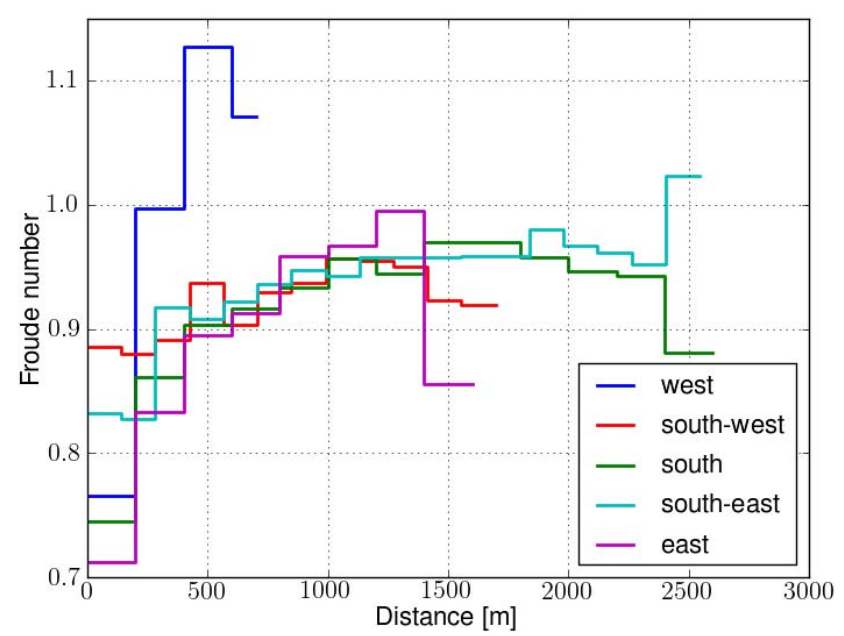

Fig. 6f. Froude numbers along wave gauge lines.

www.nat-hazards-earth-syst-sci.net/10/2359/2010/ 


\subsection{Comparison between results for different $\eta_{0}$}

So far we have only considered results for $\eta_{0}=0.23 \mathrm{~m}$. In order to test to what extent the results are sensitive to the initial wave amplitude, simulations have also been carried out for $\eta_{0}=0.46 \mathrm{~m}$ and $2.3 \mathrm{~m}$. Figure $7 \mathrm{a}$ and $\mathrm{b}$ shows a comparison of the surface elevation at two wave gauges, marked as WGA and WGB in Fig. 2, located at the northwest and south-east end of the south-east line of wave gauges. Results for $\eta_{0}=0.23 \mathrm{~m}, 0.46 \mathrm{~m}$, and $2.3 \mathrm{~m}$ have been scaled by 100,50 , and 10 , respectively, to obtain comparable results. The difference in initial wave amplitude does not have any significant influence on characteristic features of the leading wave group. Both the travel time and the group structure is preserved, but the wave amplitude for $\eta_{0}=$ $2.3 \mathrm{~m}$ deviates slightly from the two other results. Although the nonlinear effects become larger with increasing wave amplitude, nonlinear effects are likely to remain weak in the long wave part of the wave spectrum, including specifically the waves in the leading wave group. Wave breaking is also likely to be an important factor, both near the wave generating source and in the near shore region. However, the source function used in the simulations is applicable to linear waves far from the eruption center, and consequently also far from the region near the eruption center where wave transformation due to wave breaking is most likely to occur. Since the source function is partly empirical, this means that the effect of wave breaking is already parameterized within the source function formulation. As a consequence, wave predictions near the eruption site, where wave transformation due to nonlinear effects is more pronounced, are not as reliable as results for the far field.

\subsection{Simulated wave amplitude, modeled and observed wave runup}

Table 1 includes the observed runup heights at different locations around the coast of the lake, and data for the first wave arriving at numerical wave gauges at offshore locations close to where runup was measured. No suitable offshore point was found for TS19, since the waves most likely propagated along the shore to this point. A source function with initial maximum wave height of $\eta_{0}=0.23 \mathrm{~m}$ was used in the simulations. A comparison between measured runup data and simulated maximum offshore wave amplitude shows that the former is larger than the latter by a factor of approximately 300. An amplification factor of 100 is expected by the use of an equally reduced initial wave height at the source. These results indicate that there is an additional amplification factor of approximately 3, which can be considered as a typical factor for the ratio between wave runup and offshore wave amplitude. In the following analysis, an estimate of wave runup based on the simulated results is obtained by using the theoretical formulas for wave runup.

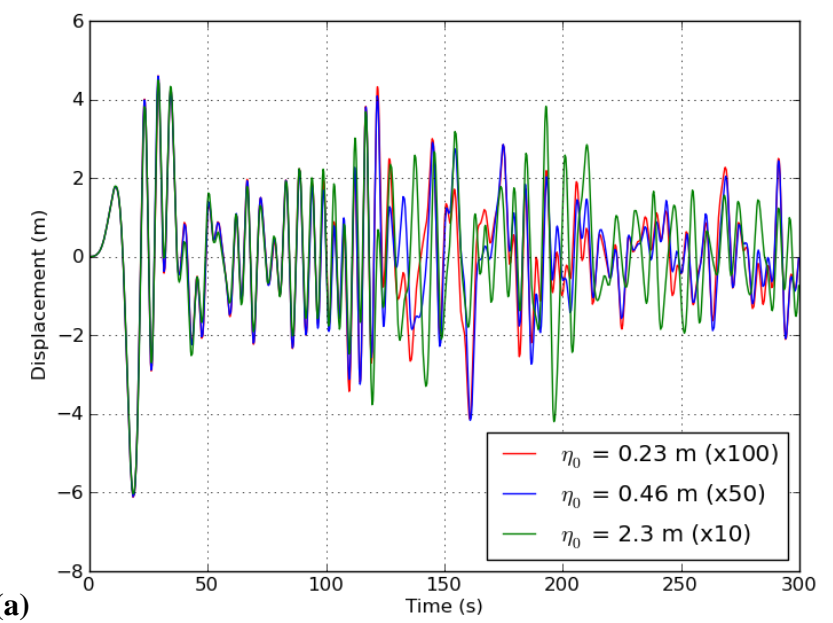

(a)

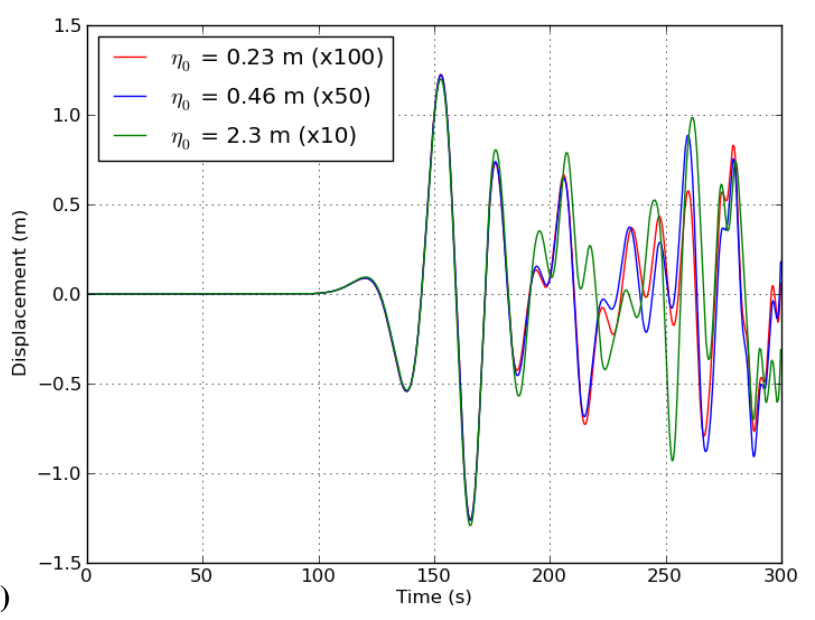

Fig. 7. Comparison between time series of surface displacement for different values of $\eta_{0}$. Wave gauge location: (a) WGA and (b) WGB.

Results at locations of the largest wave runup (TS17, TS18, and TS22) deviate from the rest of the data points. These locations are on the north-west and north part of the shore, near the source of the eruption. Highly nonlinear waves moving at an oblique angle along a steep coastline may attain unusually large amplitudes at the point of reflection at the shore. This effect has been studied extensively for solitary waves, where it has been found that Mach stem reflection, due to nonlinear interaction between the incident and reflected wave, can lead to amplitude amplification of up to 4 times the incident wave amplitude (Miles, 1977; Peterson et al., 2003). A similar type of process may occur at the coast near the eruption center, which would account for the large runup heights found at the locations TS17, TS18, TS19 and TS22.

A rough estimate for wave runup can be calculated using analytical formulas derived from nonlinear shallow water theory for sine wave runup on a beach of constant slope (Pelinovsky, 1982; Pelinovsky and Mazova, 1992; 
Table 1. Comparison between measured runup and simulated data.

\begin{tabular}{|c|c|c|c|c|c|c|c|}
\hline \multirow[t]{2}{*}{ Location } & \multirow[t]{2}{*}{ Depth $\left(h_{0}\right)$} & \multirow[t]{2}{*}{ Distance $\left(L_{0}\right)$} & \multicolumn{2}{|c|}{ Simulated data } & \multirow[t]{2}{*}{ Breaking (Br) } & \multicolumn{2}{|c|}{ Runup height } \\
\hline & & & Period & Amplitude & & Modeled & Measured \\
\hline TS1 & $6.36 \mathrm{~m}$ & $120 \mathrm{~m}$ & $12.7 \mathrm{~s}$ & $0.021 \mathrm{~m}$ & 181.5 & $20.4 \mathrm{~m}$ & $6.2 \mathrm{~m}$ \\
\hline TS2 & $4.36 \mathrm{~m}$ & $120 \mathrm{~m}$ & $17.2 \mathrm{~s}$ & $0.025 \mathrm{~m}$ & 236.7 & $23.0 \mathrm{~m}$ & $7.6 \mathrm{~m}$ \\
\hline TS3 & $9.71 \mathrm{~m}$ & $110 \mathrm{~m}$ & $11.8 \mathrm{~s}$ & $0.020 \mathrm{~m}$ & 64.5 & $17.4 \mathrm{~m}$ & $5.8 \mathrm{~m}$ \\
\hline TS4 & $19.81 \mathrm{~m}$ & $140 \mathrm{~m}$ & $19.9 \mathrm{~s}$ & $0.012 \mathrm{~m}$ & 3.9 & $7.6 \mathrm{~m}$ & $5.8 \mathrm{~m}$ \\
\hline TS5 & $13.37 \mathrm{~m}$ & $90 \mathrm{~m}$ & $23.9 \mathrm{~s}$ & $0.010 \mathrm{~m}$ & 1.6 & $5.1 \mathrm{~m}$ & $4.3 \mathrm{~m}$ \\
\hline TS6 & $9.21 \mathrm{~m}$ & $90 \mathrm{~m}$ & $17.9 \mathrm{~s}$ & $0.013 \mathrm{~m}$ & 10.1 & $8.4 \mathrm{~m}$ & $3.3 \mathrm{~m}$ \\
\hline TS7 & $13.17 \mathrm{~m}$ & $80 \mathrm{~m}$ & $18.6 \mathrm{~s}$ & $0.017 \mathrm{~m}$ & 4.0 & $9.3 \mathrm{~m}$ & $4.3 \mathrm{~m}$ \\
\hline TS8 & $15.50 \mathrm{~m}$ & $100 \mathrm{~m}$ & $18.7 \mathrm{~s}$ & $0.011 \mathrm{~m}$ & 3.1 & $6.4 \mathrm{~m}$ & $1.9 \mathrm{~m}$ \\
\hline TS9 & $6.10 \mathrm{~m}$ & $120 \mathrm{~m}$ & $26.6 \mathrm{~s}$ & $0.012 \mathrm{~m}$ & 17.9 & $8.1 \mathrm{~m}$ & $2.4 \mathrm{~m}$ \\
\hline TS 10 & $21.47 \mathrm{~m}$ & $90 \mathrm{~m}$ & $23.8 \mathrm{~s}$ & $0.016 \mathrm{~m}$ & 0.9 & $5.1 \mathrm{~m}$ & $3.8 \mathrm{~m}$ \\
\hline TS11 & $10.85 \mathrm{~m}$ & $40 \mathrm{~m}$ & $21.3 \mathrm{~s}$ & $0.017 \mathrm{~m}$ & 0.8 & $6.4 \mathrm{~m}$ & $4.8 \mathrm{~m}$ \\
\hline TS13 & $22.71 \mathrm{~m}$ & $90 \mathrm{~m}$ & $18.5 \mathrm{~s}$ & $0.008 \mathrm{~m}$ & 0.8 & $4.1 \mathrm{~m}$ & $4.3 \mathrm{~m}$ \\
\hline TS14 & $11.36 \mathrm{~m}$ & $90 \mathrm{~m}$ & $22.4 \mathrm{~s}$ & $0.019 \mathrm{~m}$ & 5.2 & $10.4 \mathrm{~m}$ & $6.2 \mathrm{~m}$ \\
\hline TS15 & $13.66 \mathrm{~m}$ & $80 \mathrm{~m}$ & $22.0 \mathrm{~s}$ & $0.021 \mathrm{~m}$ & 3.0 & $10.5 \mathrm{~m}$ & $6.2 \mathrm{~m}$ \\
\hline TS16 & $11.08 \mathrm{~m}$ & $80 \mathrm{~m}$ & $14.6 \mathrm{~s}$ & $0.020 \mathrm{~m}$ & 12.7 & $12.9 \mathrm{~m}$ & $9.0 \mathrm{~m}$ \\
\hline TS17 & $9.15 \mathrm{~m}$ & $130 \mathrm{~m}$ & $19.8 \mathrm{~s}$ & $0.022 \mathrm{~m}$ & 33.8 & $16.3 \mathrm{~m}$ & $14.0 \mathrm{~m}$ \\
\hline TS18 & $8.37 \mathrm{~m}$ & $140 \mathrm{~m}$ & $13.8 \mathrm{~s}$ & $0.026 \mathrm{~m}$ & 144.7 & $24.5 \mathrm{~m}$ & $19.0 \mathrm{~m}$ \\
\hline TS19 & - & - & - & - & - & - & $29.0 \mathrm{~m}$ \\
\hline TS20 & $8.91 \mathrm{~m}$ & $60 \mathrm{~m}$ & $22.0 \mathrm{~s}$ & $0.012 \mathrm{~m}$ & 2.2 & $5.8 \mathrm{~m}$ & $4.3 \mathrm{~m}$ \\
\hline $\mathrm{TS} 21$ & $9.24 \mathrm{~m}$ & $40 \mathrm{~m}$ & $26.9 \mathrm{~s}$ & $0.017 \mathrm{~m}$ & 0.6 & $6.0 \mathrm{~m}$ & $4.7 \mathrm{~m}$ \\
\hline TS22 & $6.31 \mathrm{~m}$ & $110 \mathrm{~m}$ & $19.4 \mathrm{~s}$ & $0.020 \mathrm{~m}$ & 49.1 & $15.1 \mathrm{~m}$ & $10.0 \mathrm{~m}$ \\
\hline $\mathrm{TS} 23$ & - & - & - & - & - & - & $6.2 \mathrm{~m}$ \\
\hline TS24 & $7.58 \mathrm{~m}$ & $120 \mathrm{~m}$ & $16.9 \mathrm{~s}$ & $0.030 \mathrm{~m}$ & 85.5 & $18.3 \mathrm{~m}$ & $4.8 \mathrm{~m}$ \\
\hline
\end{tabular}

Didenkulova et al., 2007). Based on the simulated results in Table 1, runup height can be estimated using

$$
A_{\mathrm{R}}=2 \pi A \sqrt{2 L_{0} / \lambda}
$$

where $A_{\mathrm{R}}$ is the runup height, $A$ is the wave amplitude at the offshore reference point (wave gauge), amplified by a factor $100, L_{0}$ is the distance from the offshore reference point to the shore, and $\lambda$ is the corresponding wave length for the record calculated through wave period $T$. The results are given as modeled runup height in Table 1, and are shown in the scatter diagram Fig. 8.

Most of the modeled data are of the same order of magnitude as the measured runup. The dashed line represent equivalence between modeled and measured results. Most of the data lie on a line parallel to the equivalence line, but the model overestimates the runup height compared to the measured data by $2-5 \mathrm{~m}$. There are four outliers in the scatter diagram, from measurement sites TS1-TS3, and TS24. In order to understand the physics behind these outliers, we look at the breaking parameter $\mathrm{Br}$, given by

$\mathrm{Br}=\frac{A_{\mathrm{R}}}{g}\left(\frac{2 \pi L_{0}}{T h_{0}}\right)^{2}$

where $h_{0}$ is the depth at the offshore reference point (Didenkulova et al., 2007). The breaking parameter indicates

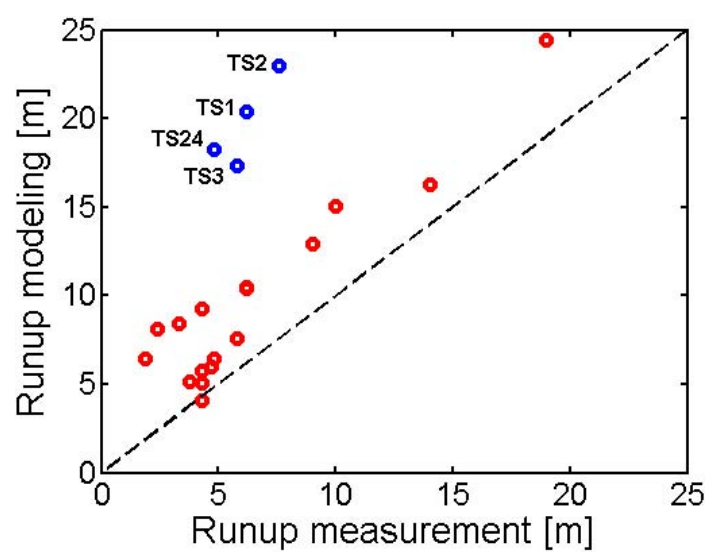

Fig. 8. Scatter diagram for measured and modeled wave runup.

that wave breaking occur if $\mathrm{Br}>1$, and larger values indicate that the waves start to break further offshore. It follows from Eq. (8) that the breaking parameter $\mathrm{Br}$ is proportional to the runup height $A_{\mathrm{R}}$ and, therefore, waves of larger amplitude break sooner. Figure 9 shows estimated and measured runup, and breaking parameter at different locations. The breaking parameter is exceptionally large at seven locations: TS1-TS3, TS17, TS18, TS22, and TS24. Among these 


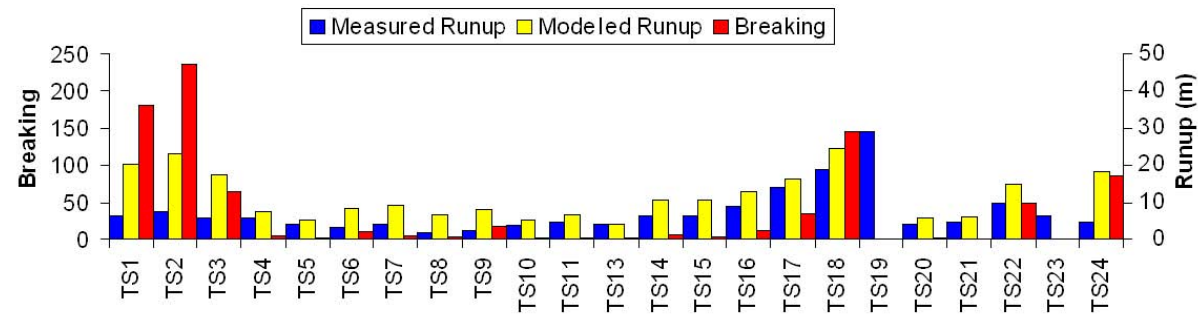

Fig. 9. Measured and modeled runup, and wave breaking analysis. Points where wave breaking is significant have the largest discrepancy between the measured and modeled wave runup (see Fig. 8).
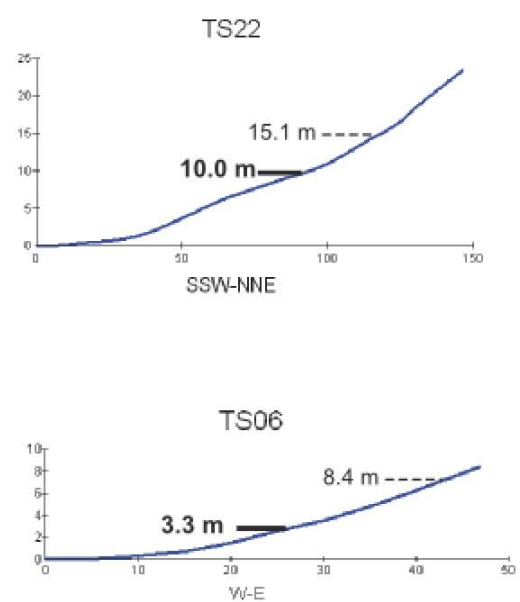

TS10

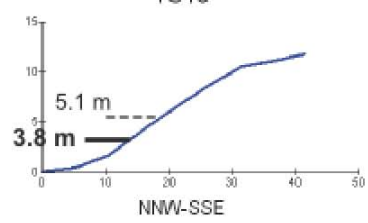

TS13

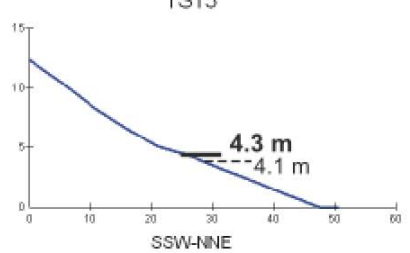

TS16

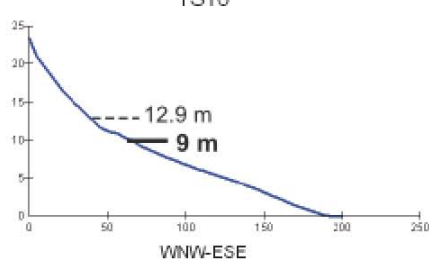

---- $11 \mathrm{~m}$ modeled runup

- $9 \mathrm{~m}$ measured runup
$\mathrm{TSO} 4$

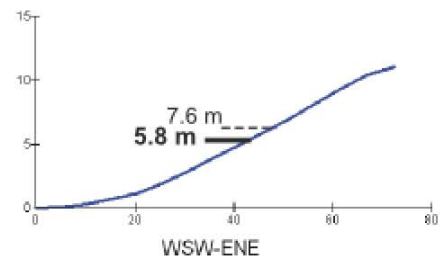

TSO8

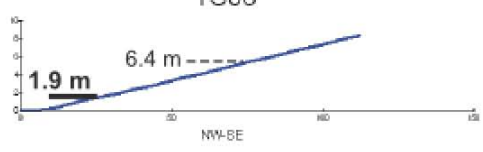

TS21

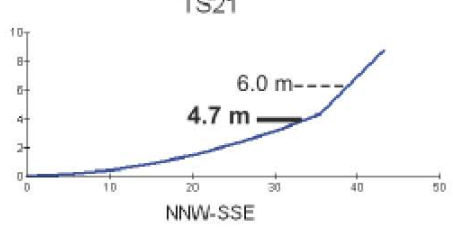

TS14

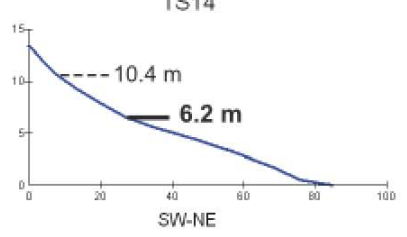

TS17

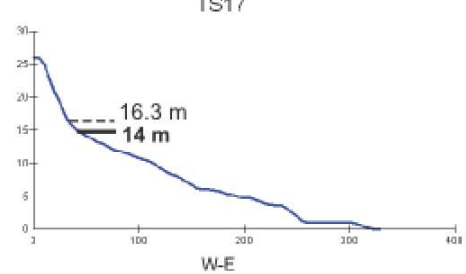

TS05
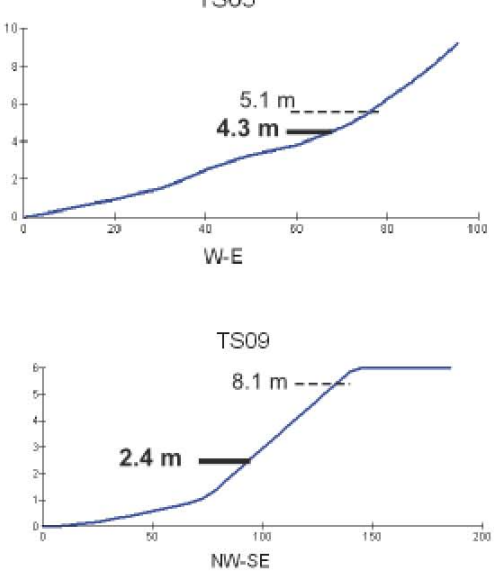

TS20

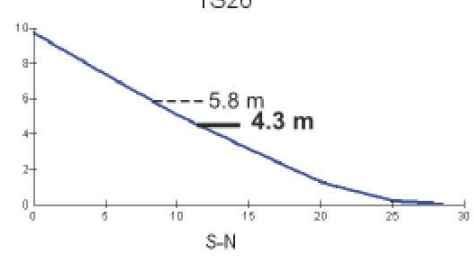

TS15

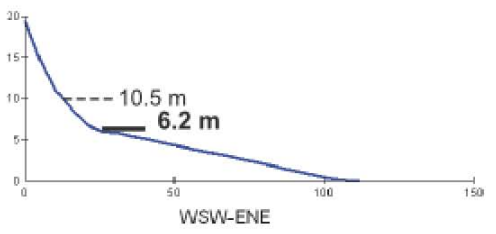

TS18

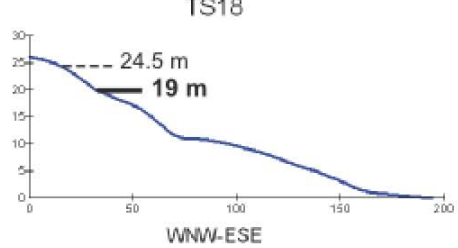

Fig. 10. Beach profiles, runup measurements, and modeled runup height. 
locations, three are in the immediate vicinity of the source (TS17, TS18, and TS22), where the breaking most likely occurs directly at the shore. Wave breaking is likely to be a significant factor for the remaining four locations (TS1TS3, and TS24), which may explain the large discrepancies between measured and modeled results at these points. Figure 10 show beach profiles included in the runup analysis, indicating both measured and modeled runup heights, for locations where the analysis indicate that wave breaking was not a significant factor.

\section{Conclusions}

Waves generated by the sublacustrine, Surtseyan-type eruption in Karymskoye caldera lake on 2-3 January 1996 have been examined by numerical simulations using a long wave Boussinesq-type model. The simulated maximum wave amplitude distribution for the leading waves (Fig. 4) is generally consistent with measured runup data (Fig. 10) along the coast of the lake. Due to numerical stability considerations, simulations were performed with reduced wave amplitude $\left(\eta_{0}=0.23 \mathrm{~m}\right)$, making the simulated waves essentially linear. The wave speed of the leading wave group is limited by the local water depth, and reach a maximum of $24 \mathrm{~m} \mathrm{~s}^{-1}$ in the deepest part of the lake. Important features such as the wave speed, period, and group structure of the leading waves are not significantly influenced by the amplitude scaling, as demonstrated by the comparison between $\eta_{0}=0.23 \mathrm{~m}, \eta_{0}=0.46 \mathrm{~m}$, and $\eta_{0}=2.3 \mathrm{~m}$ results.

Both simulated and theoretical results predict wave reduction as waves propagate away from the eruption center, but the simulated waves are generally larger than the theoretical predictions, except for eastward propagation where there is good agreement between theoretical and simulated results. However, the theoretical and simulated results seem to converge also along the other radial directions, except for westward propagation where the waves propagate along the coastline. The theoretical predictions are expected to be valid at a large distance from the wave source, and this situation is not achievable due to the limited extent of the lake. Moreover, the theoretical formula was found to give the best agreement between linear wave theory and experiments for low energy explosions $\left(E \sim 2 \times 10^{6}-3 \times 10^{10} \mathrm{~J}\right)$, whereas the kinetic energy of the simulated volcanic explosion is estimated to be of the order $E \sim 2 \times 10^{12} \mathrm{~J}$, which is possibly beyond the applicable range of the theory. It has also been indicated by Le Méhauté and Wang (1996) that the theoretical formulas need to be modified in shallow water, but these modified formulas are not available in any publications known to the authors. Considering these limitations, it is not surprising that there are some discrepancies between the theoretical and simulated results.
Comparison between runup measurements and simulated wave amplitude offshore measurement sites show a clear correlation for locations far from the eruption center. The present model setup does not capture nonlinear effects believed to be particularly important in the coastal region near the eruption site. Estimated results for wave runup are of the same order of magnitude as measurements, except near the source of the eruption and at a few locations where the analysis shows significant wave breaking.

Considering all these parameters, such simulations are suitable for assessing tsunami hazards related to volcanic explosions. Many lakes and sea bays over the world are of volcanic origin or partly occupied by recent eruptive vents, and their shores are often densely populated. Surprisingly, tsunamis are commonly neglected in volcanic hazards scenarii and the present contributions may help in introducing tsunamis in future studies on volcanic hazard assessment in lacustrine and sea bay environments.

Acknowledgements. This research was conducted with support from ANR (French National Research Agency) project 08JCJC-0042 "Vitesss - Volcano-Induced Tsunamis: numErical Simulations and Sedimentary Signature". Didenkulova and Torsvik received support from Marie Curie network SEAMOCS (MRTN-CT-2005-019374) and EEA grant (EMP41). Pelinovsky was supported by grants RFBR 08-05-00096 and 09-05-91222. Belousovs thank the Earth Observatory of Singapore for support during preparation of this paper. This is EOS contribution \#14.

Edited by: S. Monserrat

Reviewed by: C. Waythomas and F. Maeno

\section{References}

Begét, J.: Volcanic tsunamis, in: Encyplopedia of Volcanoes, edited by: Sigurdsson, H., Houghton, B., Mc Nutt, S., Rymer, H., and Stix, J., Academic Press, 1005-1013, 2000.

Bellotti, G., Di Risio, M., and De Girolamo, P.: Feasibility of Tsunami Early Warning Systems for small volcanic islands, Nat. Hazards Earth Syst. Sci., 9, 1911-1919, doi:10.5194/nhess-91911-2009, 2009.

Belousov, A. and Belousova, M.: Eruptive process, effects and deposits of the 1996 and ancient basaltic phreatomagmatic eruptions in Karymskoye lake, Kamchatka, Russia, in: Volcaniclastic Sedimentation in Lacustrine Settings, edited by: White, J. and Riggs, N., Blackwell, International Association of Sedimentologists Special Publications, 30, 235-260, 2001.

Belousov, A., Voight, B., Belousova, M., and Muravyev, Y.: Tsunamis generated by subaquatic volcanic explosions: unique data from 1996 eruption in Karymskoye lake, Kamchatka, Russia, Pure Appl. Geophys., 157, 1135-1143, 2000.

Didenkulova, I., Pelinovsky, E., Soomere, T., and Zahibo, N.: Runup of nonlinear asymmetric waves on a plane beach, in: Tsunami \& Nonlinear Waves, edited by: Kundu, A., Springer, 14, 175-190, 2007. 
Freundt, A., Strauch, W., Kutterolf, S., and Schmincke, H.-U.: Volcanogenic Tsunamis in Lakes: Examples from Nicaragua and General Implications, Pure Appl. Geophys., 164, 527-545, 2007. Geist, E., Lynettb, P. J., and Chaytorc, J. D.: Hydrodynamic modeling of tsunamis from the Currituck landslide, Mar. Geol., 264, 41-52, 2009.

Korycansky, D. and Lynett, P.: Run-up from impact tsunami, Geophys. J. Int., 170, 1076-1088, 2007.

Latter, J. H.: Tsunamis of Volcanic Origin: Summary of Causes with Particular Reference to Krakatoa, 1883, B. Volcanol., 44, 467-490, 1981.

Le Mehaute, B.: Theory of explosion-generated water waves, in: Advances in Hydroscience, edited by: te Chow, V., Academic Press, New York, London, 7, 1-79, 1971.

Le Méhauté, B. and Wang, S.: Water Waves Generated by Underwater Explosion, in: Advanced Series on Ocean Engineering - Volume 10, World Scientific, 1996.

Lynett, P. and Liu, P. L.-F.: A Numerical Study of Submarine Landslide Generated Waves and Runup, P. Roy. Soc. Lond A, 458, 2885-2910, 2002.

Lynett, P., Wu, T.-R., and Liu, P. L.-F.: Modeling Wave Runup with Depth-Integrated Equations, Coast. Eng., 46, 89-107, 2002.
Miles, J. W.: Resonantly interacting solitary waves, J. Fluid Mech., 79, 171-179, 1977.

Mirchina, N. R. and Pelinovsky, E. N.: Estimation of Underwater Eruption Energy Based on Tsunami Wave Data, Nat. Hazards, 1, 277-283, 1988.

Pelinovsky, E. and Mazova, R.: Exact analytical solutions of nonlinear problems of tsunami wave run-up on slopes with different profiles, Nat. Hazards, 6, 227-249, 1992.

Pelinovsky, E. N.: Nonlinear Dynamics of Tsunami Waves, Applied Physics Institute Press, 1982.

Peterson, P., Soomere, T., Engelbrecht, J., and van Groesen, E.: Soliton interaction as a possible model for extreme waves in shallow water, Nonlin. Processes Geophys., 10, 503-510, doi:10.5194/npg-10-503-2003, 2003.

Torsvik, T., Didenkulova, I., Soomere, T., and Parnell, K. E.: Variability in spatial patterns of long nonlinear waves from fast ferries in Tallinn Bay, Nonlin. Processes Geophys., 16, 351-363, doi:10.5194/npg-16-351-2009, 2009a.

Torsvik, T., Pedersen, G., and Dysthe, K.: Waves Generated by a Pressure Disturbance Moving in a Channel with a Variable Cross-Sectional Topography, J. Waterw Div.-ASCE, 135, 120 123, 2009b. 